\title{
Study of histopathological patterns of endometrium in abnormal uterine bleeding
}

\author{
Anitha S., Pooja G.*, Sowmya D.
} Department of Obstetrics and Gynaecology, A. J. Institute of Medical Sciences and Research Centre, Mangalore,
Karnataka, India

Received: 25 February 2021

Accepted: 15 March 2021

*Correspondence:

Dr. Pooja G.,

E-mail: poojagopu1@gmail.com

Copyright: (c) the author(s), publisher and licensee Medip Academy. This is an open-access article distributed under the terms of the Creative Commons Attribution Non-Commercial License, which permits unrestricted non-commercial use, distribution, and reproduction in any medium, provided the original work is properly cited.

\begin{abstract}
Background: Abnormal uterine bleeding (AUB) is the commonest presenting symptom in gynaecology out- patient department. Endometrial sampling could be effectively used as the first diagnostic step in AUB. This study was done to evaluate histopathology of endometrium for identifying the endometrial causes of AUB. And also, to observe the incidence of various endometrial pathology in different age groups presenting with abnormal uterine bleeding.

Methods: A one-year prospective study conducted in the department of obstetrics and gynaecologist in A. J. institute of medical sciences and research centre which included 200 cases of clinically diagnosed AUB patients. Histopathological examination of endometrial biopsies specimens was done, followed by clinical correlation.

Results: The most common age group presenting with AUB was 41-50 years (43.84\%). The commonest pattern in these patients was normal cycling endometrium (42.32\%). The commonest pathology irrespective of the age group was disordered proliferative pattern $(26.15 \%)$. Other causes identified atrophic endometrium $(11.5 \%)$, benign endometrial polyp (5.38\%), endometrial hyperplasia (5.41\%), carcinomas (0.79\%) and chronic endometritis $(1.54 \%)$.

Conclusions: The knowledge of endometrial pattern in a case of AUB helps to decide a plan of management. Endometrial sampling plays a very important role in management of AUB, especially in the age group of more than 40 years; i.e., the peri and post-menopausal age groups, where incidence of malignant or pre malignant conditions was noted to be the highest.
\end{abstract}

Keywords: Abnormal uterine bleeding, Endometrial cancer, Endometrial sampling, Endometrial hyperplasia

\section{INTRODUCTION}

Abnormal uterine bleeding (AUB) is defined as bleeding from the uterine corpus that is abnormal in regularity, volume, frequency or duration and occurs in the absence of pregnancy. ${ }^{1}$ The prevalence of AUB varies in each country it is reported to occur in 9 to $14 \%$ women between menarche and menopause. ${ }^{2}$ In India, the reported prevalence of AUB is around 17.9\%. ${ }^{3}$ At about $70 \%$ of premenopausal women presents with complaints of AUB in gynaecology OPD. ${ }^{4}$ Descriptive terms that traditionally have been used to characterize abnormal menstrual bleeding patterns include menorrhagia, metrorrhagia, polymenorrhea, and oligomenorrhea. ${ }^{5}$

Traditionally descriptive terms like menorrhagia ,metrorrhagia , polymenorrhea and oligomenorrhea have been used for AUB in 2011 a new classification system (polyp, adenomyosis, leiomyoma, malignancy and hyperplasia, coagulopathy, ovulatory dysfunction, endometrial, iatrogenic, and not yet classified), known by the acronym PALM-COEIN, was introduced by the international federation of gynaecology and obstetrics (FIGO). ${ }^{1}$ In the new classification system PALM side refers to structural causes that could be evaluated and 
diagnosed on imaging and or biopsy. The COEIN side allows consideration of underlying medical disturbances that could result in AUB.

The term AUB is paired with descriptive terms to denote bleeding patterns, such as heavy menstrual bleeding (instead of menorrhagia) and intermenstrual bleeding (instead of metrorrhagia). A thorough medical history, physical examination, appropriate laboratory and imaging tests, consideration of age-related factors should be included in the evaluation of AUB. ${ }^{7}$

In patients presenting with AUB the role of endometrial sampling is to rule out endometrial carcinoma or premalignant lesions of endometrium, although other pathology related to bleeding may be found. Endometrial tissue sampling should be performed in patients with AUB who are older than 45 years and also in patients younger than 45 years with a history of unopposed estrogen exposure (such as seen in obesity or PCOS), failed medical management, and persistent AUB. ${ }^{7}$

Endometrial carcinoma is the one of the commonest gynaecological malignancies. and its precursor, endometrial hyperplasia, usually presents with AUB. ${ }^{8}$ Endometrial hyperplasia is estimated to have at least three times higher incidence than endometrial carcinoma and if detected early, can prevent many women from developing endometrial carcinoma. ${ }^{9}$

The underlying disease can be detected by histological patterns of endometrium through biopsy or curettage which is a safe and effective diagnostic method in the evaluation of AUB considering the age, menstrual cycle phase and use of exogenous hormones. The importance of endometrial curettage done to obtain material for histopathological evaluation to aid in diagnosis and further management cannot be over emphasized especially in perimenopausal and post- menopausal age groups..$^{10}$

The aim and objective of the study is to analyse different histopathological patterns of endometrium in AUB and observe the incidence of various pathologies in different age groups.

\section{METHODS}

This is prospective observational study conducted from October 2018-November 2019 in the department of obstetrics and gynaecology, A. J. institute of medical sciences and research centre after obtaining ethical committee approval.

A total of 200 patients who presented with a clinical diagnosis of AUB and who gave consent to participate were enrolled in the study. Patients with isolated endometrial causes of abnormal uterine bleeding were included for the study and those with leiomyoma, cervical, vaginal pathology, haemostatic disorders and pregnancy related complications were excluded.

Detailed clinical history including age, pattern and duration of abnormal bleeding, menstrual history, obstetric history, use of exogenous hormones, physical examination findings including pelvic examination and investigations were recorded. The specimen was received as endometrial curettage and endometrial biopsy. All specimens were fixed in $10 \%$ formalin and sent for histopathological examination to look for various histopathological patterns of endometrium.

Data was entered in Microsoft excel sheet systematically. Analysis was done and statistics was taken out in percentages for all variables.

\section{Inclusion criteria}

Patients with isolated endometrial causes of AUB were included in the study.

\section{Exclusion criteria}

Isolated cervical and vaginal pathology, leiomyoma, haemostatic disorders and pregnancy related complications were excluded from the study.

\section{RESULTS}

With the clinical diagnosis of AUB 200 patients have been enrolled in the study out of which 130 patients are associated with isolated endometrial causes who have been evaluated for AUB. Majority of the women who presented with clinical diagnosis are between the age group of 41-50 years (Table 1). The most common histopathological pattern in this age group was cyclical endometrium (includes proliferative and secretory endometrium).

Table 1: Distribution according to the age of presentation.

\begin{tabular}{|lll|}
$\begin{array}{l}\text { Age groups } \\
\text { (year) }\end{array}$ & $\begin{array}{l}\text { No: of women } \\
(\mathbf{n = 1 3 0})\end{array}$ & $\begin{array}{l}\text { Percentage } \\
(\%)\end{array}$ \\
\hline$\leq \mathbf{2 0}$ & 1 & 0.79 \\
\hline $\mathbf{2 1 - 3 0}$ & 16 & 12.3 \\
\hline $\mathbf{3 1 - 4 0}$ & 35 & 26.95 \\
\hline $\mathbf{4 1 - 5 0}$ & 57 & 43.84 \\
\hline $\mathbf{5 1 - 6 0}$ & 15 & 11.5 \\
\hline $\mathbf{> 6 0}$ & 6 & 4.63 \\
\hline
\end{tabular}

The commonest histopathological finding observed in the study was cyclical endometrium (42.32\%). Disordered proliferative endometrium was observed in $26.15 \%$. Endometrial Hyperplasia was observed in $5.41 \%$ out of which atypical endometrial hyperplasia was seen in $1.54 \%$. In this study endometrial carcinoma was observed in 1 patient (Table 2). 
Atrophic endometrium is observed in postmenopausal age group of about $11.5 \%$ of the patients (Table 3 ).
Other causes of AUB like endometrial polyp is seen in $5.38 \%$, endometritis in $1.54 \%$ of the cases.

Table 2: Distribution of histopathological pattern of endometrium.

\begin{tabular}{|lll|}
\hline Type of histopathological pattern of endometrium & No. of patients $(\mathbf{n}=\mathbf{1 3 0})$ & Percentage $(\boldsymbol{\%})$ \\
\hline Cyclical endometrium & 55 & 42.32 \\
\hline Disordered proliferative endometrium & 34 & 26.15 \\
\hline Atrophic endometrium & 15 & 11.5 \\
\hline Pill endometrium & 9 & 6.93 \\
\hline Atypical endometrial hyperplasia & 2 & 1.54 \\
\hline Non atypical endometrial hyperplasia & 5 & 3.87 \\
\hline Endometrial polyp & 7 & 5.38 \\
\hline Endometritis & 2 & 1.54 \\
\hline Endometrial carcinoma & 1 & 0.77 \\
\hline
\end{tabular}

Table 3: Distribution of cases of abnormal uterine bleeding.

\begin{tabular}{|c|c|c|c|c|c|c|c|}
\hline \multirow[b]{2}{*}{$\begin{array}{l}\text { Histopathological pattern } \\
\text { of endometrium }\end{array}$} & \multicolumn{6}{|c|}{ Age group (year) } & \multirow[b]{2}{*}{$\begin{array}{l}\text { Total } \\
(\%)\end{array}$} \\
\hline & $\begin{array}{l}\leq 20 \\
(n=1)\end{array}$ & $\begin{array}{l}21-30 \\
(n=16)\end{array}$ & $\begin{array}{l}31-40 \\
(n=35)\end{array}$ & $\begin{array}{l}41-50 \\
(n=57)\end{array}$ & $\begin{array}{l}51-60 \\
(n=15)\end{array}$ & $\begin{array}{l}>60 \\
(\mathrm{n}=6)\end{array}$ & \\
\hline Cyclical endometrium & 1 & 6 & 15 & 31 & 3 & - & 42.32 \\
\hline $\begin{array}{l}\text { Disordered proliferative } \\
\text { endometrium }\end{array}$ & - & 4 & 12 & 14 & 3 & - & 26.15 \\
\hline Atrophic endometrium & - & - & - & 6 & 5 & 4 & 11.5 \\
\hline Pill endometrium & - & 2 & 5 & 2 & - & - & 6.93 \\
\hline Endometrial carcinoma & - & - & - & - & - & 1 & 0.79 \\
\hline Endometrial polyp & - & 3 & 3 & 1 & - & - & 5.38 \\
\hline $\begin{array}{l}\text { Atypical endometrial } \\
\text { hyperplasia }\end{array}$ & - & - & - & - & 2 & - & 1.54 \\
\hline Endometritis & - & 1 & - & 1 & - & - & 1.54 \\
\hline $\begin{array}{l}\text { Non atypical } \\
\text { Endometrial hyperplasia }\end{array}$ & - & - & - & 2 & 2 & 1 & 3.87 \\
\hline Total (\%) & 0.79 & 12.3 & 26.95 & 43.84 & 11.5 & 4.63 & 100 \\
\hline
\end{tabular}

\section{DISCUSSION}

Abnormal uterine bleeding is a term that describes irregularities in the menstrual cycle involving frequency, regularity, duration and volume of flow outside of pregnancy. A normal menstrual cycle has a frequency of 21-35 days, last 5-7 days with less than $80 \mathrm{ml}$ of blood loss. Variations in any of these parameters constitute AUB. ${ }^{7}$

Routine non-invasive investigations for AUB were carried out which included complete blood count, platelet count, liver function test, prothrombin time, activated partial thromboplastin time, to rule out bleeding and coagulation disorder. In a woman of reproductive age group, serum or urine HCG was evaluated to rule out pregnancy. As thyroid is the commonest endocrinological cause encountered, thyroid function test was done. ${ }^{11}$

On ruling out these, Endometrial sampling was done as a diagnostic procedure. Etiology of AUB relates to the patients age as to whether the patient is premenopausal, perimenopausal or postmenopausal. The most common age group presenting with AUB in this study was 41-50 years. Similar observations were made by Simridhi et al in 2018 and Bolde et al. ${ }^{10,12}$

Histopathological examination of the endometrial biopsies and curettingg revealed various patterns ranging from physiological to pathological lesions of the endometrium. In this study the most common the histopathological findings were cyclical endometrium (proliferative/secretory) which is $42.32 \%$. This pattern was commonly observed in the late reproductive and perimenopausal women, may be due to the hormonal imbalance in this group leading to intermittent anovulatory cycles. ${ }^{13,14}$.

Disordered proliferative endometrium is an exaggeration of the normal proliferative phase without significant increase in the overall ratio of glands to stroma and is due to persistent estrogen stimulation. This pattern is particularly seen in perimenopausal women. ${ }^{6,15}$ Disordered proliferative pattern lies at one end of the spectrum of proliferative lesions of the endometrium that includes carcinoma at the other end with intervening 
stages of hyperplasia. In this study disordered proliferative endometrium was observed in $26.15 \%$, which was slightly higher when compared with other studies. An earlier stage of presentation due to increase health awareness could explain high incidence in our study. ${ }^{20}$

The incidence of endometrial hyperplasia in this study $(5.11 \%)$ was less as compared to other studies as these patients may have been identified at a much earlier stage that is in the disordered proliferative phase. ${ }^{19}$ Endometrial hyperplasia is a precursor of endometrial cancer. It is more commonly seen during the perimenopausal period. As endometrial hyperplasia is a precursor of endometrial cancer, with overall risk of progression to cancer being 5$10 \%$, its identification is important in peri and postmenopausal patients presenting with abnormal uterine bleeding. ${ }^{10}$ In this study endometrial cancer is seen in 1 patient who presented with a postmenopausal bleeding.

Atrophic endometrium is the most common cause of bleeding in postmenopausal stage. ${ }^{16}$ Thin-walled veins, superficial to the expanding cystic glands, make the vessels vulnerable to injury and lead to excessive uterine bleeding. ${ }^{17}$ Atrophic endometrium was seen in $11.5 \%$ of the patients in this study, similar to study conducted by Simridhi et al. ${ }^{10}$

In our study, pill endometrium was seen in $6.93 \%$ cases. Other studies reported a lower incidence. This was probably due to increased number of patients in this age resorting to early medical management for bleeding. ${ }^{18}$ The other benign patterns included endometrial polyps (5.38\%), endometritis (1.54\%) which is similar to other studies.

Limitations of the study is a small sample size and the menstrual phase during which the endometrial sample was taken is not mentioned in the study.

\section{CONCLUSION}

Endometrial cause of abnormal uterine bleeding is age related pathology. Histopathological examination of endometrial biopsy is a major diagnostic tool in evaluation of abnormal uterine bleeding and a specific diagnosis could help in the management of abnormal uterine bleeding.

\section{ACKNOWLEDGMENTS}

The authors would like to thanks for support and cooperation of all the patients involved in the study.

Funding: No funding sources Conflict of interest: None declared

Ethical approval: The study was approved by the Institutional Ethics Committee

\section{REFERENCES}

1. Munro MG, Critchley HO, Broder MS, Fraser IS. FIGO classification system (PALM-COEIN) for causes of abnormal uterine bleeding in nongravid women of reproductive age. FIGO Working Group on Menstrual Disorders. Int J Gynaecol Obstet. 2011;113:3-13.

2. Fraser IS, Langham S, Uhl-Hochgraeber K. Healthrelated quality of life and economic burden of abnormal uterine bleeding. Expert Rev Obstet Gynecol. 2009;4:179-89.

3. Sharma A, Dogra Y. Trends of AUB in tertiary centre of Shimla hills. J Midlife Health. 2013;4:67-8.

4. Pillai SS. Sonographic and histopathological correlation and evaluation of endometrium in premenopausal women with abnormal uterine bleeding. Int J Reprod Contracept Obstet Gynecol. 2014;3:113-7.

5. Fraser IS, Critchley HO, Munro MG, Broder M. A process designed to lead to international agreement on terminologies and definitions used to describe abnormalities of menstrual bleeding. Writing Group for this Menstrual Agreement Process [published erratum appears in Fertil Steril. Fertil Steril 2007;87:466-76.

6. Mazur MT, Kurman RJ. Normal endometrium and infertility evaluation. In: Mazur MT, Kurman RJ, editors. Diagnosis of endometrial biopsies and curettings: A practical approach. $2^{\text {nd }}$ ed. New York: Springer Verlag. 2005;7-33.

7. ACOG practice bulletin Diagnosis of abnormal uterine bleeding in reproductive aged women January 2012. Obstetrics and Gynecol. 2012;120(1):197-206.

8. RCOG Green top guideline no. 67, management of endometrial hyperplasia. 2016.

9. Reed SD, Newton KM, Clinton WL, Epplein M, Garcia R, Allison K et al. Incidence of endometrial hyperplasia. Am J Obstet Gynecol. 2009;200:678:16.

10. Simridhi B, Monika G, Tajinder K. Histopathological spectrum of endometrium in abnormal uterine bleeding. Intl J Reprod Contra Obstet Gynecol. 2018;7(9):3633-7.

11. Albers JR, Hull SK, Wesley RM. Abnormal uterine bleeding. Am Fam Phys. 2004;69:1915-26.

12. Bolde SA, Pudale SS, Pandit GA, Matkari PP. Histopathological study of endometrium in cases of abnormal uterine bleeding. Int $\mathrm{J}$ Res Med Sci. 2017;2(4):1378-81.

13. Doraiswami S, Johnson $\mathrm{T}$, Rao S, Rajkumar A, Vijayaraghavan J, Panicker VK. Study of endometrial pathology in abnormal uterine bleeding. J Obstet Gynaecol India. 2011;61(4):426-30.

14. Perveen S, Perveen S. Endometrium histology in abnormal uterine bleeding. Med Channel. 2011;17(4):68-70.

15. Mutter GL. Diagnosis of premalignant endometrial disease. J Clin Pathol. 2002;55:326-31. 
16. Cornitescu FI, Tănase F, Simionescu C, Iliescu D. Clinical, histopathological and therapeutic considerations in non-neoplastic abnormal uterine bleeding in menopause transition. Rom J Morphol Embryol. 2011;52:759-65.

17. Baral R, Pudasini S. Histopathological pattern of endometrial samples in abnormal uterine bleeding. $\mathrm{J}$ Path Nepal 2011;1:13-6.

18. Kaliyath S, Shetty P, Jayaprakash S, Permi K, Panna $\mathrm{H}$. Study of histopathological patterns of endometrium in abnormal uterine bleeding. Chrismed J health res. 2014;1:76-81.
19. Saroj A. Histopathological study of endometrium in cases of abnormal uterine bleeding. Int $\mathbf{J}$ Res Med Sci. 2017;2(4):1378-81.

20. Chauhan S, Radhakrishnan K. Clinical profile of endometrial histopathological patterns in Abnormal Uterine Bleeding. Nepal J Obstetr Gynaecol. 2020;15(1):50-4.

Cite this article as: Anitha S, Pooja G, Sowmya D. Study of histopathological patterns of endometrium in abnormal uterine bleeding. Int J Reprod Contracept Obstet Gynecol 2021;10:1401-5. 